\title{
Motivation and engagement in mathematics: a qualitative framework for teacher-student interactions
}

\author{
Tracy L. Durksen ${ }^{1}$ • Jennifer Way ${ }^{2}$ - Janette Bobis ${ }^{2}$ • \\ Judy Anderson ${ }^{2}$ - Karen Skilling ${ }^{3}$. \\ Andrew J. Martin ${ }^{1}$
}

Received: 31 August 2016 / Accepted: 8 February 2017 /

Published online: 25 February 2017

(C) Mathematics Education Research Group of Australasia, Inc. 2017

\begin{abstract}
We started with a classic research question (How do teachers motivate and engage middle year students in mathematics?) that is solidly underpinned and guided by an integration of two theoretical and multidimensional models. In particular, the current study illustrates how theory is important for guiding qualitative analytical approaches to motivation and engagement in mathematics. With little research on how teachers of mathematics are able to maintain high levels of student motivation and engagement, we focused on developing a qualitative framework that highlights the influence of teacher-student interactions. Participants were six teachers (upper primary and secondary) that taught students with higher-than-average levels of motivation and engagement in mathematics. Data sources included one video-recorded lesson and associated transcripts from pre- and post-lesson interviews with each teacher. Overall, effective classroom organisation stood out as a priority when promoting motivation and engagement in mathematics. Results on classroom organisation revealed four key indicators within teacher-student interactions deemed important for motivation and engagement in mathematics - confidence, climate, contact, and connection. Since much of the effect of teachers on student learning relies on interactions, and given the universal trend of declining mathematical performance during the middle years of schooling, future research and intervention studies might be assisted by our qualitative framework.
\end{abstract}

Tracy L. Durksen

tracy.durksen@unsw.edu.au

1 School of Education, Faculty of Arts and Social Sciences, University of New South Wales, 131 John Goodsell Bldg, Sydney, NSW 2052, Australia

2 The University of Sydney, Sydney, NSW 2006, Australia

3 King's College London, Strand, London WC2R 2LS, UK 
Keywords Teacher-student relationship - Mathematics education - Student motivation Student engagement $\cdot$ Teacher-student interactions

\section{Introduction}

Theoretically driven empirical research on mathematics education is critical since mathematics provides key skills and knowledge for achieving success at school, work, and in everyday life. Research focused on motivation and engagement in mathematics is particularly important since low student engagement is considered a determining factor in the universal trend of declining mathematical performance during a critical period in students' lives - the transition into secondary school (MCEETYA 2008). Mounting evidence (e.g. Martin and Marsh 2006) points to relationships between low levels of student engagement and academic underachievement, lower participation and retention rates at school, and lower global self-esteem. To help researchers investigate these relationships, we elaborate on the theoretical foundation that has grounded related investigations of student motivation, engagement, and mathematics achievement in Australia (Anderson et al. 2016). Specifically, we focus on teacher-student interactions at a time when students are transitioning from upper primary (ages 10-11) to the first 2 years (ages 12-13) of secondary school.

Many studies of achievement motivation and engagement have focused on the student experience, often from an atheoretical or single theoretical perspective. Although researchers such as Pintrich et al. (1991) have contributed significant works in this field from a multidimensional theoretical position, traditional approaches to the study of motivation and engagement in mathematics tend to be focused on one theoretical framework or are unidimensional in their operationalisation. Thus, we sought to explore how a diverse and encompassing approach that draws on salient factors from numerous theoretical traditions can be helpful in effectively answering our research question: How do teachers motivate and engage middle year students in mathematics? Although motivation and engagement often overlap in the literature, we distinguish between the two and agree with Gettinger and Walter's (2012) use of motivation as a student's intention or willingness to act and engagement as the student's actual involvement. Though distinguishable, the inter-related indicators of motivation and engagement can contribute to our understanding of a student's classroom experience with mathematics. This inter-relationship can be defined as agentic engagement - a student's positive motivational involvement or agency in teacher-student interactions (Cheon and Reeve 2015; Reeve and Tseng 2011). Therefore, we chose to approach the study of student-level motivation and engagement with The Motivation and Engagement Wheel (Martin 2007) and integrate this model with a teacher-level model (The Classroom Assessment Scoring System; Pianta and Hamre 2009).

\section{A multidimensional foundation for student motivation and engagement in mathematics}

With our aim of building a qualitative framework for analysing how teachers motivate and engage middle year students in mathematics, we considered Martin's (2007) Motivation and Engagement Wheel (hereafter referred to as the Wheel). The Wheel has operationalised an inter-related combination of constructs from six key theories of 
achievement motivation (for an integrative discussion, see Martin and Dowson 2009): attribution theory (Weiner 1985), expectancy-value theory (Wigfield and Eccles 2000), goal theory (Elliot and McGregor 2001), self-determination theory (SDT; Ryan and Deci 2000), self-efficacy theory (Bandura 1997), and self-worth motivation theory (Covington 1992). As displayed through Fig. 1, the Wheel is grounded in multiple theories of achievement motivation and includes both positive and negative factors. Describing each underpinning theory of the Wheel is beyond the scope of this article, but SDT serves as a particularly relevant theory for teacher-student interactions. Namely, SDT identifies relatedness as an intrinsic motivator that can be satisfied within a supportive learning environment. This is of interest in the current study since teachers' offering of one-on-one support is considered an important contribution to a positive classroom climate (Klassen et al. 2012).

The theoretically grounded Wheel (Martin 2007) has been successfully validated through quantitative applications to mathematical learning (e.g. Bobis et al. 2011). The 11 factors of the Wheel align with Fredricks et al.'s (2004) three components of engagement: behavioural, cognitive, and emotional. According to Fredricks et al., behavioural engagement pertains to physical participation, cognitive engagement involves the thought-driven or willingness to put forth effort, and emotional engagement is defined by the learner's activation of positive and negative feelings and affect in class. In the Wheel, behavioural engagement is defined through positive (planning, task management, and persistence) and negative factors (disengagement and selfhandicapping behaviours). Cognitive motivational factors are identified in the Wheel as positively influencing engagement (self-efficacy, mastery orientation, and valuing)

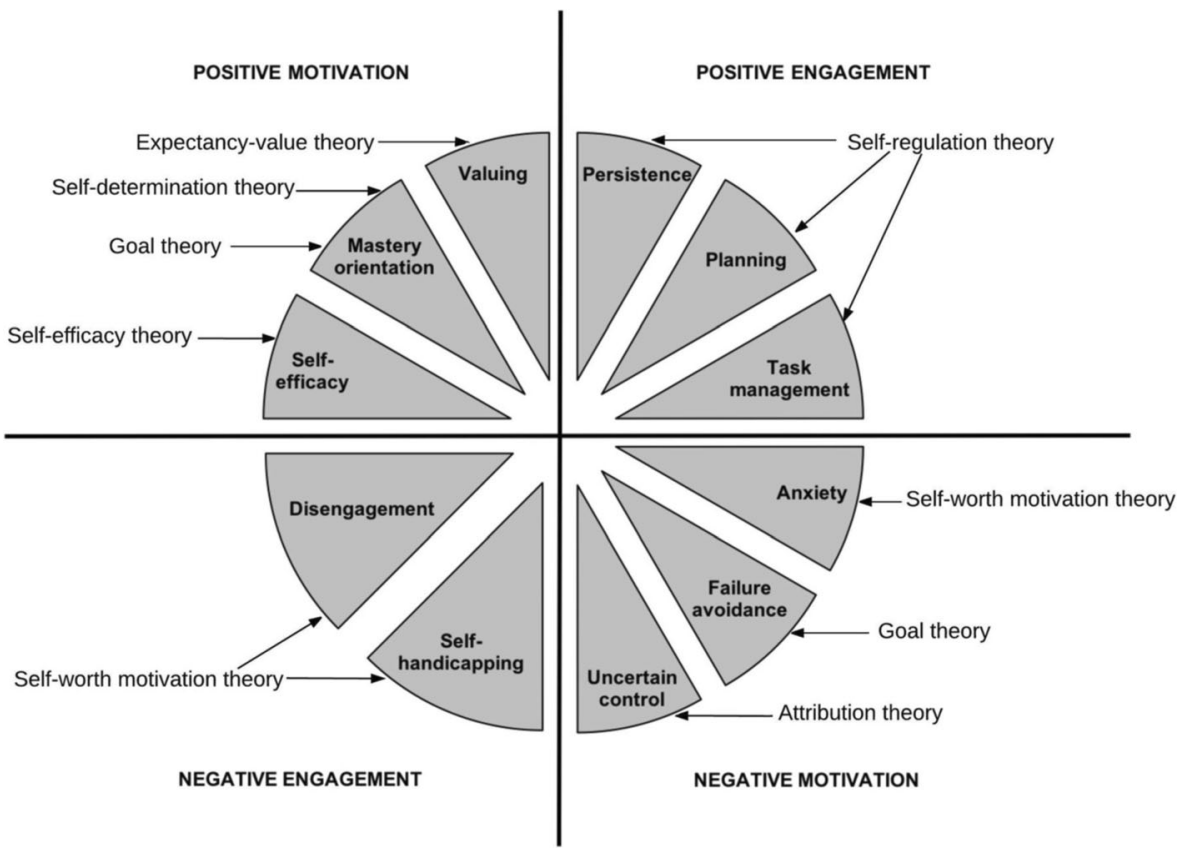

Fig. 1 The Motivation and Engagement Wheel (reproduced with permission from Martin, A. J. and Lifelong Achievement Group) with examples of theoretical underpinnings. A number of academic motivation theories have been operationalised through the Wheel; some of which are presented in this figure 
or negatively influencing engagement (uncertain control, failure or performance avoidance, and anxiety). Overall, the factors of the Wheel represent a diverse theory-driven framework for research aimed at explaining motivation and engagement.

Since emotional engagement is not as prominently represented through the Wheel, attention to a range of emotions can help accentuate the mirroring of some of the Wheel factors. For example, Salmela-Aro et al. (2008) identified emotional disengagement (negative engagement) when a student is cynical about the value (positive motivation) of school and coursework. Thus, we chose to supplement the Wheel with an emotionfocused framework (Circumplex Structure of Core Affect; Yik et al. 2011). With more than half of 15-year olds reportedly experiencing frequent instances of anxiety in mathematics (OECD 2010), it is not uncommon to find a focus on negative emotions in the research (e.g. Goetz et al. 2013). However, since positive emotions as predictors of motivation in mathematics have also garnered interest by researchers (e.g. Hanin and Nieuwenhoven 2016), we considered additional emotions beyond those identified in the Wheel (anxiety, value).

\section{Teacher-level supports for student motivation and engagement in mathematics}

We identified a second theoretically based model as an important complement to the Wheel for our investigation. To help capture the teacher-level supports that influence student motivation and engagement, we included The Classroom Assessment Scoring System $^{\text {TM }}$ (CLASS ${ }^{\text {TM}}$; Pianta and Hamre 2009) — a model grounded in developmental theory (e.g. bioecological theory; Bronfenbrenner 1986). The CLASS ${ }^{\text {TM }}$ was particularly appropriate for our investigation since previous research found teacher-student interactions as the most influential on the effectiveness of intervention studies in mathematics (e.g. Confrey 2006; Slavin et al. 2009). While the Wheel identifies factors of student motivation and engagement, the CLASS ${ }^{\mathrm{TM}}$ provides a way to assess observable and related teacher-level supports in the classroom. According to Pianta et al. (2012), teacher-student interactions across all grade levels are the "primary mechanism of student development and learning" (p. 1) and can be broadly measured by three domains: emotional support, classroom organisation, and instructional support. When developing our qualitative framework, we incorporated the CLASS ${ }^{\text {TM }}$ domains since Pianta and colleagues deem them developmentally appropriate for examining mathematical learning in the middle years.

Table 1 provides an overview of the CLASS ${ }^{\text {TM }}$ components with examples of categories and associated indicators specific to an upper primary or secondary school classroom. The CLASS ${ }^{\text {TM }}$ measure guides a trained observer to attend to what Martin and Dowson (2009) refer to as connective instruction, that is, the "who, what, and how of everything that is happening at the classroom level, with particular attention to the teachers' instructional interactions and behaviours" (Pianta et al. 2012, p. 7). This differs from a teacher's connectivist orientation that is described by Askew and colleagues (Askew et al. 2000; Askew et al. 1997) as explicit connections made among mathematical concepts within a community of learners. While Askew et al. (2000) consider a mathematics teacher with an orientation towards making connections among numeracy concepts as most effective (i.e. in terms of learning outcomes measured 
through a test of numeracy), connective instruction places the focus on explicit motivation and engagement strategies dependent on teacher-student relationships.

\section{The current study}

The current study is situated within a large mixed-methods project (see description by Bobis et al. 2016) designed to research the decline in mathematics engagement and achievement during the middle years of schooling. The larger project used crosssectional and longitudinal research designs with quantitative and qualitative methods in order to discover broad pedagogical characteristics of mathematics teachers and inform an intervention program. With an initial sample of 4383 students in 47 schools (257 classrooms), results revealed the majority of variance in engagement shifts in mathematics occurred at the student level, with little at the class or school level (Martin et al. 2015). Therefore, we sought to draw attention to individualised teacher-student interactions in promoting student motivation and engagement.

Phase One of the larger project centred on Martin's Wheel (2007) with students in 37 schools completing the associated quantitative scale (Martin 2008). After results confirmed an overall decline in motivation and engagement in mathematics across the middle years (Martin et al. 2012), we identified cohorts and individual students of both high and low motivational and engagement levels. Phase Two included interviewing

Table 1 Summary of CLASSTM framework

\begin{tabular}{|c|c|c|c|}
\hline Domains & Dimensions & Categories (examples) & $\begin{array}{l}\text { Indicators } \\
\text { (examples) }\end{array}$ \\
\hline \multirow[t]{3}{*}{ Emotional support } & Positive climate & Relationships & $\begin{array}{l}\text { Shared positive } \\
\text { affect }\end{array}$ \\
\hline & Teacher sensitivity & Student comfort & $\begin{array}{l}\text { Seeks } \\
\text { support/guidance }\end{array}$ \\
\hline & $\begin{array}{l}\text { Regard for adolescent } \\
\text { perspectives }\end{array}$ & Connections to current life & $\begin{array}{l}\text { Communicates } \\
\text { usefulness }\end{array}$ \\
\hline \multirow[t]{3}{*}{$\begin{array}{l}\text { Classroom } \\
\text { organisation }\end{array}$} & Behaviour management & Clear expectations & $\begin{array}{l}\text { Students know what } \\
\text { to do }\end{array}$ \\
\hline & Productivity & Transitions & Little wasted time \\
\hline & Negative climate $^{\mathrm{a}}$ & Disrespect & $\begin{array}{l}\text { Exclusionary } \\
\text { behaviour }\end{array}$ \\
\hline \multirow[t]{5}{*}{$\begin{array}{l}\text { Instructional } \\
\text { support }\end{array}$} & $\begin{array}{l}\text { Instructional learning } \\
\text { formats }\end{array}$ & $\begin{array}{l}\text { Variety of } \\
\text { modalities/strategies/materials }\end{array}$ & Interactive materials \\
\hline & Content understanding & $\begin{array}{l}\text { Opportunity for practice of } \\
\text { procedures/skills }\end{array}$ & Independent practice \\
\hline & Analysis and inquiry & Metacognition & Students reflect \\
\hline & Quality of feedback & Encouragement and affirmation & $\begin{array}{l}\text { Encourage } \\
\text { persistence }\end{array}$ \\
\hline & Instructional dialogue & Facilitation strategies & Students respond \\
\hline Overall & Student engagement & Active engagement & Volunteering \\
\hline
\end{tabular}

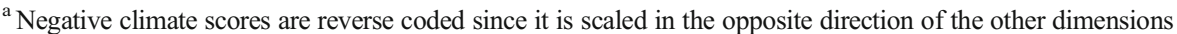
(higher negativity indicates lower quality of teacher-student interactions) (Pianta et al. 2012)
} 
students who had experienced significant upward or downward shifts in their motivation and engagement over a 12-month period (Skilling et al. 2015) and the beliefs and practices of the teachers of the same students (Skilling et al. 2016). During Phase Three, we examined teachers and classrooms exhibiting higher-than-average levels of student motivation and engagement and concluded with an intervention during Phase Four (Bobis et al. 2016). The current study is situated within Phase Three.

\section{Methods}

\section{Participants and data sources}

Six cases were purposefully selected and defined by the six participating teachers (two upper primary and four secondary) who had classes of students with higher-thanaverage $^{1}$ motivation and engagement in mathematics. All participants (two males, four females) were either trained as secondary mathematics teachers or primary generalists with mathematics as a preferred teaching subject. One primary teacher had more than 21 years of teaching experience (seven as a teacher in the upper primary level of mathematics). The second primary teacher had been teaching for less than 10 years and had spent approximately half of her experience as a teacher in the upper primary level of mathematics. The four secondary teachers also had a range of experience: two with less than 6 years of experience and two with more than 16 years teaching experience. Since the six cases had already been identified through the larger project as similar, our focus was on whether these six cases, when analysed together, could contribute process-related findings.

The goal of extending the findings of one exploratory case study (Way et al. 2015) and a study that included case analyses of the four secondary classrooms (Skilling 2013) influenced our selection of data sources. Since Way et al. (2015) found high incidences of teacher-student interactions in one case study, we sought to explore the five additional cases to see if they predicted the same results (i.e. literal replication; Yin 2003). According to Yin (2003), an important step in the multiple-case process is the "development of a rich theoretical framework" (p. 47) and in the case of literal replication, the framework needs to state the likely conditions. As our investigation focused on teachers with the same levels of motivation and engagement among students in mathematics, we were able to develop a framework specific to those conditions. An intended outcome, then, was to produce a framework that can be used as a "vehicle for generalizing to new cases" (p. 49). Thus, we started with three sources of data associated with each participating teacher: transcripts from semi-structured interviews (before and after each teacher's lesson observation), video-recorded lesson observations (one per teacher), and quantitative data from the Teacher Beliefs and Practices Survey which included 20 statements about teachers' beliefs and practices regarding reform-oriented mathematics teaching (adapted from Ross et al. 2003).

\footnotetext{
${ }^{1}$ The comparative level of motivation and engagement was determined by the scores on the Motivation and Engagement Scale completed by students in over 200 classes during the larger project (see Martin et al. 2015).
} 


\section{Analytical strategy}

Our analyses of multiple data sources were guided by two key models (the Wheel and CLASS ${ }^{\text {TM}}$ ). Our strategy involved four steps with the goal of developing an integrated framework for future qualitative investigations. During step 1, we applied the Wheel when coding pre- and post-lesson interview transcripts within NVivo 10 (QSR International 2014). Since we found that the Wheel primarily represented behavioural and cognitive components, we supplemented our coding with the Circumplex Structure of Core Affect (Yik et al. 2011) to help identify additional emotional components of motivation and engagement. The circumplex was an appropriate addition to our coding structure since, like the Wheel, it was developed through an integration of multidimensional models. Organised according to valence (unpleasant to pleasant) and activation (low to high arousal), Yik and colleagues detail 12 key factors within their "parsimonious representation of the correlational structure of mood and emotion" (p. 707). As a result, our code structure included pleasant and high arousal emotions (e.g. happy, excited), pleasant and low arousal emotions (e.g. pleased, calm) as well as unpleasant and high arousal emotions (e.g. mad, afraid), and unpleasant and low arousal emotions (e.g. bored, defeated). Overall, this approach allowed for a focus on the teachers' descriptions of students' motivational processes that were considered internal and therefore typically unobservable.

Whereas the Wheel helped frame teachers' descriptions, the CLASS ${ }^{\text {TM }}$ helped focus on observable teacher-student interactions (step 2). As displayed earlier through Table 1, the CLASS ${ }^{\text {TM }}$ measures emotional support, classroom organisation, and instructional support along with a student engagement indicator that serves as a global measure of student functioning (Pianta et al. 2012). A trained and certified CLASS ${ }^{\text {TM }}$ observer selected video-recorded observations based on Pianta et al.'s (2012) criteria and procedures (e.g. 15- to 20-min video selection per teacher). Following each video observation, the observer used the validated behaviourally anchored set of rating scales in the CLASS ${ }^{\text {TM }}$ observer manual (Pianta et al. 2012) for coding teacher-student interactions during one mathematics lesson. Although the manual was specific for observations in secondary classrooms, the developers (Pianta et al. 2012) found the scales appropriate for upper primary years as well.

For step 3, we compared the CLASS ${ }^{\text {TM }}$ ratings of each teacher with the coded transcripts that detailed each teacher's pre- and post-lesson process. Here, we integrated our results by categorising coded transcript examples using the CLASS ${ }^{\mathrm{TM}}$ domains. We also compared our integrated results with the survey results on the teachers' beliefs and practices (e.g. student confidence, teacher's role; Ross et al. 2003). For triangulation (Yin 2003), the survey data helped provide a more holistic view of each teacher but did not contribute any further information to our qualitative framework for teacher-student interactions. Lastly, step 4 involved displaying a representation of the integrated results through a proposed framework.

Both the Wheel and CLASSTM were deemed reliable for the purposes of the current study. As part of the inter-rater reliability process, we used group discussion to evaluate the initial coding that was based on the Wheel. Once we had established a refined code structure, two team members independently coded $10 \%$ of the transcript data with results that were later used to compare with the lead coder's results. Using Miles and Huberman's (1994) inter-rater reliability formula (of comparing agreements to 
disagreements), we achieved $83 \%$ agreement. Lastly, the first author engaged in theoretical discussions with the author of the Wheel (Martin 2007), which helped further confirm our coding of the transcripts. Reliability of the CLASS ${ }^{\text {TM }}$ for scoring video-recorded lessons was established through the observer's certification requirement, which involves the maintenance of high-reliability results through annual testing.

\section{Results and theoretical interpretations}

Given the theoretical focus of this paper, we present both results and corresponding interpretations within this section. First, we present examples from the interview transcripts organised broadly by the Wheel. Next, we present a summary of results from the video-recorded lessons that were analysed using the CLASS ${ }^{\mathrm{TM}}$ rating scale. Lastly, we present a proposed integrative framework that emerged and can be applied during future qualitative analyses.

\section{Student motivation in mathematics}

When coding the interview transcripts for what the teacher says about maintaining or promoting student motivation in mathematics, we referenced the Wheel's positive factors of motivation. We also coded what the teacher says about addressing or reducing negative/low student motivation in mathematics by referencing the negative motivation factors. Results highlight the teacher-student relationship and how motivation can be particularly influenced through one-on-one interactions. For example, one participant shared: "I think if you get on with your students and they want you around and they enjoy that one-on-one help then it is going to help them a lot...there is no one strategy that you use." In fact, one teacher recognised how a focus on instructional strategies can negatively impact mathematical learning: "When I first started I had a whole lot of hands on activities...then I was just behind [and] they really only understood half of the course content that they were meant to know." Rather than identifying specific instructional strategies, the participating teachers often reported on the influence that interpersonal support had on motivation and the importance of maintaining a positive climate:

...during the warm-up [activity], I make sure that I go over and give a little comment... a little bit of positive praise. I'm more of a one-on-one type. [I'll also] ask them how they are going and that's good for your own [rapport] with the student...it's all in the question. They feel non-threatened.

With motivation defined as a set of beliefs and emotions that influence and direct behaviour (Martin 2007), it was not surprising to find a range of emotions during our coding process. By supplementing the Wheel with the Circumplex Structure of Core Affect, we were able to code a range of emotions. For example, one teacher personalised emotions of enjoyment and boredom in the mathematics classroom:

You have to make it fun for yourself. If it is boring I don't want to be there either...I guess you have to look at it as not just standing in front of the room and 
trying to transfer what you know to them...they need to be engaged, you need to be engaged - you want to be.

We also found positive emotions tied to self-efficacy or mathematical confidence (positive motivation). For example, while discussing how students' felt when concepts were introduced in relation to future mathematics expectations, a participating teacher observed little fear:

...they [were] pretty positive so I definitely think it is a confidence thing... making sure they fully get it [now]...I have got quite an inquisitive bunch of students so they are always pretty keen to know more and so it is good.

We also identified participants' examples of student confidence as integral to persistence (positive engagement):

...the kids that have a bit more confidence in themselves and a bit more of a belief that they can do the work, even if they struggle a bit more with it, [they are] a bit more engaged because they want to do well and they want to keep improving...

Similarly, confidence was associated with a student's willingness to try different strategies when attempting to solve a mathematics problem: “...[I help] build their confidence... if they can believe they can do it...that gives them the courage to risk again and try something different." One teacher, however, described lack of confidence as negative motivation (e.g. failure or performance avoidance), stemming from an unattainable task or goal:

Since we started [using] the same common assessment across the board, the ones that are doing the intermediate [and] moreso the standard [curriculum] have just lost interest, they're disheartened by the fact that they can't achieve and it's very very difficult to get them motivated ...there are support systems for them, there is extra work given to them, there's a lot of explanation... but some of them just feel defeated.

While descriptions of negative motivation did emerge, our application of the Wheel allowed us to move beyond coding the emotion-related negative motivation factor (anxiety) and, instead, revealed how teachers' reported attempts at reducing the negative often focused on eliciting alternate and positive emotional responses (e.g. interest or enjoyment). Overall, a student's motivation in mathematics - that willingness to try different solutions and persist-appeared to be promoted through a safe and predictable classroom climate. Participating teachers often highlighted the importance of comfort through comments such as: "I think it is enough of a non-threatening area and environment that they can [try] without fear...they are comfortable with what they can do and they can get on with it and they can see improvement." A teacher's awareness of how the environment they set up can help reduce mathematics performance anxiety also came through comments such as: 
I think I have a pretty relaxed approach...it is not very intense, it is all very nice and relaxed and calm and sometimes that carries over [to] creating sort of a nice gentle calm environment. It's not frantic, it's not over the top and there is no pressure on them to perform...they don't feel threatened...they don't throw any barriers up.

One teacher reported on the influence of organisation when recounting how "a couple of girls [said] 'I was really frightened' (they did not want to do fractions). But now with the way it's organised, they are really enjoying Maths." Overall, participating teachers were more likely to discuss the importance of classroom organisation for student motivation than any other type of strategy.

\section{Student engagement in mathematics}

Engagement within the context of teacher-student interactions can provide evidence of connective instruction. When applying the Wheel, we found evidence specific to agentic engagement through what the teacher recognises as encouraging students' agency in mathematical learning. While self-efficacy or mathematical agency is a factor of positive motivation in the cognitive sense, agentic engagement in the mathematics classroom was represented as a more behavioural component of engagement. Although confidence was often extended through behavioural actions, descriptions also included evidence of emotional engagement. Behavioural examples included volunteering ("They love to come up [and] be a volunteer...they have always got their hand up reaching for the sky") and proximity ("it's funny how they sit themselves... usually the needy ones [are] up front... they just need that security"). Cognitive examples included being comfortable with "telling [the teacher] when they don't understand," putting "their hand up...watching the board... asking questions [and] even sometimes [seeing] them asking themselves questions." Emotional indicators of agentic engagement were either observable (e.g. "...they have got those quizzical looks...so if they are not falling asleep I think that is good") or explicit (e.g. "... [the students] saying they are enjoying it. It's non-threatening...I think it's just the fact that they never get in trouble for asking questions, no-one's going [to get] mad at them."

As with student motivation, participating teachers emphasised the influence of classroom organisation on student engagement. They highlighted predictability, structure (e.g. "they really enjoy the structure"), and simplicity (e.g. "I try not to overcomplicate things...if you start throwing in too much then they can just get confused and it is better to narrow it down... keep it free"). Structure in terms of clear expectations was considered influential (e.g. "you set up these structures in the first three or four weeks so [they] are very clear what you want and how the lessons will run [and] it becomes internalised") as was the use of time (e.g. "the pace of the lesson is important especially with a divided group...if you prolong things by giving them too much time then you are inviting some sort of problem with attention and they will go off and do something else"). For example, when students work in pairs, a participating teacher found tight time limits (e.g. 30 second) useful because "it really focuses them on the task." Teachers were also likely to engage students through self-assessment opportunities such as a reflective journal, survey, or closing activity (e.g. " ...[I] try to finish on a positive note [by asking] who is happy with what they have done"). For example, one teacher administered 
surveys (to be completed by students anonymously online) with results indicating positive emotional engagement among the majority: “...one of the questions [asked] if they enjoy doing problem solving and challenging tasks...80\% said [yes]."

Participating teachers also reported interpersonal interactions such as eye contact or being in close proximity to hear on-task comments as evidence of the positive influence they are having on students' engagement in mathematics. When asked how they know their students are engaged, answers included "You can see it in lots of ways...in their faces to start with...the eye contact" and "I [hear] 'I love doing this' pretty often, particularly from the ones that [don't] consider themselves to be [of high ability]." Teachers reported attending to non-verbal signs of agentic engagement through one-onone interactions - with specific recognition of the importance of eye contact. For example:

I think engagement is when the kids really connect with it. You can see it in their eyes, you can see it when they have a sense of achievement, accomplishment, surprise, all those feelings that come through...they don't want to stop because it is something they feel now they can handle or they are enjoying.

Here, the teacher reported on students expressing confidence and willingness to continue through eye contact. Similarly, our participating teachers identified how important it is to respond to students who used eye contact to signal help-seeking through examples such as: "I check in with her to try to keep her engaged in class...I have to be very careful to make sure [I respond] when she gives me that lost look", "Some of them will just be staring at me looking confused", and "You can tell by the look on their face...If you don't ask them, you don't know."

While our coding results primarily pointed to evidence of positive engagement through behavioural and emotional components, student's cognitive engagement strategies such as planning and task management were difficult to identify through the transcripts in the context of teacher-student interactions. The cognitive component of engagement as being less obvious than behavioural or emotional engagement may be tied to a teacher's focus on a student's more immediate motivational needs (Skilling and Stylianides 2015). Here, we found that when cognitive engagement strategies such as planning or task management were reported, examples were more often at the teacherlevel (e.g. modelling behaviours). Persistence as an indicator of cognitive engagement, however, was more likely to be described as relating to the student's actions or behaviours: "They're always interested, they're always willing to try. It doesn't matter if it's a steep mountain, [they'll] give it a go...if I gave them something [they] would apply themselves to it."

Given that we purposefully selected teacher data associated with higher-thanaverage levels of student engagement in mathematics, we expected little evidence of negative engagement. What we did find was evidence of what the teacher says to address or reduce negative or low engagement in mathematics. Providing real-life connections and explaining the value (positive motivation) were often strategies reportedly used by participating teachers. For example, one teacher explained, "I try and combat [disengagement by saying] well if you're going into a trade, you're going to [need to] know this..." while others identified value for upper primary students by referencing content that will be useful when in secondary mathematics. Here, the focus 
was on helping students get comfortable with a skill or procedure (i.e. mastery orientation) that will be important to know later. Overall, the interview transcripts revealed more evidence on the unobservable components of the Wheel (positive and negative motivation), than for engagement through teacher-student interactions.

\section{Teacher-level supports for students in mathematics}

Results from analysing video-recorded lessons with the CLASS ${ }^{\text {TM }}$ rating scales provided observable evidence of teacher-student interactions in mathematics. Table 2 presents the CLASS ${ }^{\text {TM }}$ scores for each of the six cases as calculated for each domain and for overall student engagement. As displayed, classroom organisation was the strongest domain of influence on students for five out of the six teachers (one teacher appeared slightly more influential through emotional support). Also evident through Table 2 is the high CLASS ${ }^{\text {TM }}$ scores for overall student engagement across the six teachers, thus providing support for the high levels of engagement found in the related Motivation and Engagement Scale quantitative results (Martin et al. 2015).

When considering the three teacher-level supports in influencing student motivation and engagement in mathematics, it is important to acknowledge the specific dimensions and indicators recognised within the CLASS ${ }^{\mathrm{TM}}$. For example, as displayed earlier through Table 1, both emotional support and classroom organisation include classroom climate indicators. Emotional support includes a positive climate dimension where the focus is on assessing relationships, positive affect, positive communications, and respect. Classroom organisation, on the other hand, includes a dimension of negative climate (negative affect, punitive control, and disrespect) used to assess an overall level of negativity between a teacher and students. Since participating teachers tended to score higher on the CLASS ${ }^{\mathrm{TM}}$ for emotional support and classroom organisation, high levels of student motivation and engagement in mathematics were primarily associated with a positive teacher-student relationship experienced within a supportive environment.

\section{An integrated framework for teacher-student interactions in mathematics}

Our results from theoretically driven analyses that were guided by the Wheel and CLASS $^{\text {TM }}$ helped confirm the reportedly high motivation and engagement levels

Table 2 Summary of CLASS ${ }^{\mathrm{TM}}$ scores for six mathematics teachers of highly engaged students

\begin{tabular}{llllll}
\hline Teacher & $\begin{array}{l}\text { Emotional } \\
\text { support }\end{array}$ & $\begin{array}{l}\text { Classroom } \\
\text { organisation }\end{array}$ & $\begin{array}{l}\text { Instructional } \\
\text { support }\end{array}$ & $\begin{array}{l}\text { Student } \\
\text { engagement }\end{array}$ & $\begin{array}{l}\text { Total score } \\
/ 84\end{array}$ \\
1 & $18 / 21(85.7 \%)$ & $21 / 21(100 \%)$ & $28 / 35(80 \%)$ & $7 / 7(100 \%)$ & $74(88 \%)$ \\
2 & $14 / 21(66.7 \%)$ & $19 / 21(90.5 \%)$ & $28 / 35(80 \%)$ & $6 / 7(85.7 \%)$ & $67(80 \%)$ \\
3 & $16 / 21(76.2 \%)$ & $21 / 21(100 \%)$ & $22 / 35(62.9 \%)$ & $6 / 7(85.7 \%)$ & $65(77 \%)$ \\
4 & $10 / 21(47.6 \%)$ & $18 / 21(85.7 \%)$ & $25 / 35(71.4 \%)$ & $6 / 7(85.7 \%)$ & $59(70 \%)$ \\
5 & $16 / 21(76.2 \%)$ & $17 / 21(81 \%)$ & $23 / 35(65.7 \%)$ & $6 / 7(85.7 \%)$ & $62(74 \%)$ \\
6 & $20 / 21(95.2 \%)$ & $19 / 21(90.5 \%)$ & $28 / 35(80 \%)$ & $6 / 7(85.7 \%)$ & $73(87 \%)$ \\
\hline
\end{tabular}

Italic values indicate the strongest domain of influence 
among students of participating teachers. Therefore, we proceeded to integrate the Wheel and CLASS ${ }^{\text {TM }}$ by categorising coded interview transcript examples using CLASS $^{\text {TM }}$ domains. The final step of our analysis process produced Fig. 2 as an illustration of an integrated framework for qualitative analyses, operationalised through the Wheel and CLASS ${ }^{\mathrm{TM}}$. Overall, we found that participating teachers were more likely to report strategies for increasing positive motivation and engagement that could be categorised as classroom organisation. For example, teachers highlighted the importance of effective behaviour management (e.g. clear expectations, proactive), managing class productivity (e.g. structured lessons), and awareness as to how a negative climate can impact students' learning.

By integrating findings guided by the Wheel with results from the CLASS ${ }^{\mathrm{TM}}$, we also concluded that teachers in our study primarily helped increase students' positive motivation or reduce negative motivation through interactions that were high in emotional and instructional support. Moreover, increasing positive engagement or reducing negative engagement often involved teacher practices specific to instructional support and effective classroom organisation. In summary, this process revealed four key indicators of effective teacher-student interactions: student confidence in mathematics, positive climate, contact (i.e. relatedness), and connections (e.g. value).

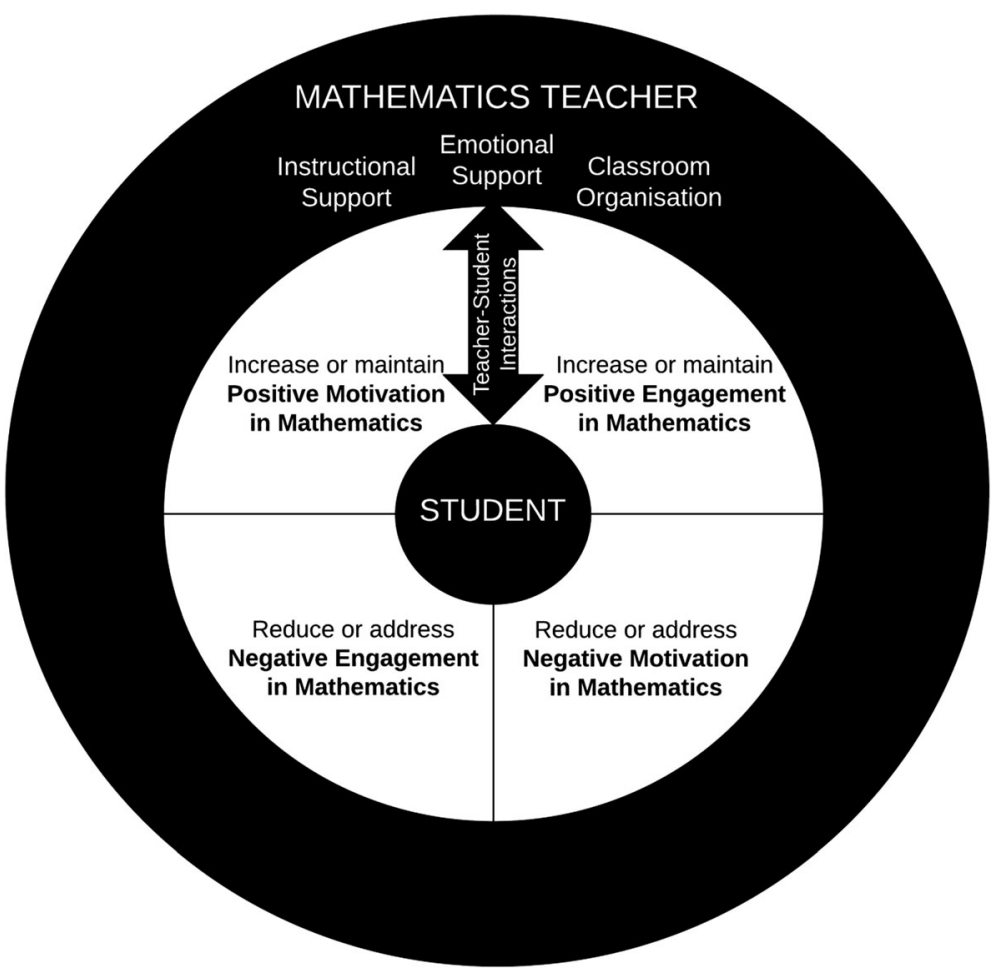

Fig. 2 An overarching framework of teacher-student interactions in mathematics. The four key themes of the Wheel (positive and negative motivation and engagement) and the three key teacher-level supports of CLASS $^{\mathrm{TM}}$ (emotional support, instructional support, and classroom organisation) together provide an integrative and theory-driven perspective on the influence of teacher-student interactions in mathematics 
Figure 3 displays a summary of our results as an example of how to apply our qualitative framework.

\section{Discussion}

How do teachers motivate and engage middle year students in mathematics? In the current study, we sought to answer this question by demonstrating how theory is critical to effectively understanding motivation and engagement in mathematics. The answer to our research question specifically has theoretical implications for extending our understanding of teacher-student interactions. The current study provided evidence that a qualitative application of the Wheel can complement the original quantitative application when examining motivation and engagement in mathematics classrooms. Together with the CLASS ${ }^{\mathrm{TM}}$, we were able to develop a framework that is centred with the Wheel and represents an integrative theoretically based approach to qualitatively describing teacher-level supports that influence students' motivation and engagement in mathematics.

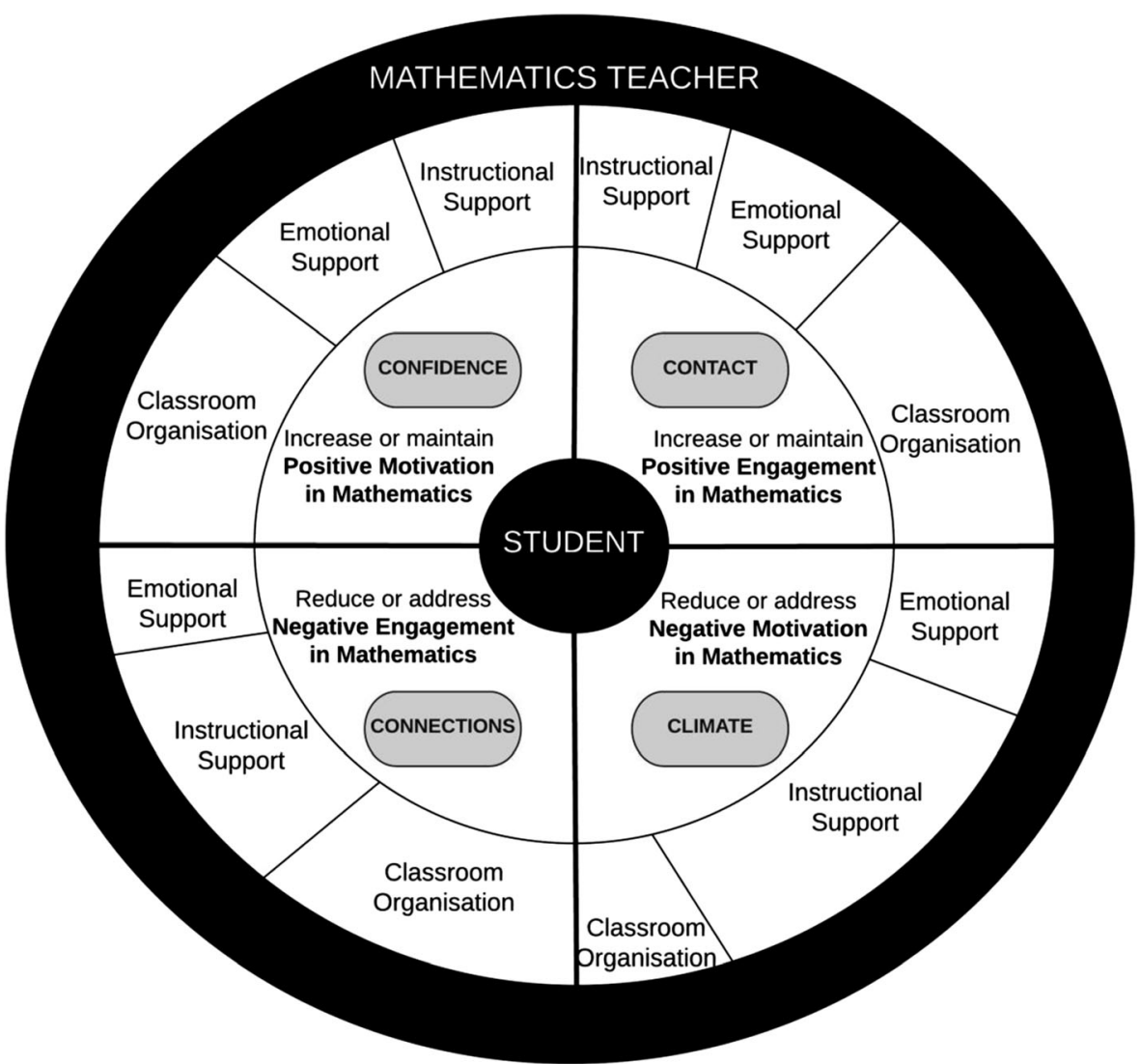

Fig. 3 An illustration of qualitative results using the integrated framework of teacher-student interactions in mathematics. This figure presents a visual summary of our study that resulted from integrating our Wheelbased findings and our CLASS-based findings 


\section{Limitations}

This study focused on expanding our theoretical understanding of students' motivation and engagement in mathematics during the middle years of schooling. Given that teachers in our study were selected based on high levels of student-reported motivation and engagement, it is perhaps not surprising that we found more frequent practices aimed at promoting positive motivation and engagement. Applying this framework to other cases (e.g. mathematics teachers with students exhibiting low levels of motivation and engagement) may provide contrary evidence. Through our multiple-case study, we were able to focus on teacher-student interactions using the Wheel and CLASS ${ }^{\mathrm{TM}}$ observational rating scales. Although we did not focus on specific characteristics of individual students in relation to their mathematics teachers, future research could apply our framework when examining how teachers can potentially overcome broader influences of a student's developmental change or parental support (Martin et al. 2015).

\section{Theoretical implications and future research}

Given that the theoretical grounding of the Wheel included self-determination theory (Ryan and Deci 2000; Deci and Ryan 2015), we were able to highlight and find support for the importance of relatedness in the teaching of mathematics. While the psychological needs of competence and autonomy are often a focus in education, relatedness - that psychological need for feeling connected within supportive relationshipsis beginning to receive more attention in studies framed by self-determination theory (e.g. Durksen et al. 2016). In the context of mathematics, relatedness may be satisfied through teacher-student interactions in the classroom, particularly when a teacher responds (e.g. reinforcing, scaffolding, adapting instruction) to a student's agentic actions (e.g. help-seeking) during those critical transitional years. By extension, we would also expect a mathematics teacher's professional agency - the relational capacity to motivate learning in a reciprocal way (Pietarinen et al. 2016) - to coincide with this type of agentic engagement. Future research is needed in order to elaborate further on the implications of agentic engagement in relation to the established models incorporated into our framework.

Together with the CLASSTM, we were able to focus specifically on teacher-student interactions as a way of understanding student motivation and engagement in mathematics. Since it is the "quality of interaction between a student and a teacher that conjoins affective and cognitive realms in the process of aiming for mathematical learning", we call for future research involving qualitative analyses that reveal the quality of teacher-student interactions (Hackenberg 2010, p. 237). One option would be to apply our framework when comparing student engagement in mathematics with engagement in a different subject (e.g. English). For example, based on the range of observational experience held by the certified CLASS ${ }^{\mathrm{TM}}$ observer of the current study, we would posit that instructional support strategies eliciting high levels of content understanding (e.g. opportunities for independent practice of procedures and skills) may be more frequently observed as an important component of motivation and engagement in mathematics classrooms when compared with other subjects.

While the larger project included an intervention phase (Bobis et al. 2016), future studies would benefit from a longitudinal examination of both student and teacher 
motivation and engagement in order to inform intervention development. A recent meta-analysis of studies related to classroom organisation proposed a classification for interventions: teachers' behaviour-focused, teacher-student relationship-focused, students' behaviour-focused, and students' social-emotional development-focused interventions (Korpershoek et al. 2016). Future research on teacher-student relationshipfocused interventions is needed, particularly since Korpershoek et al. (2016) revealed only two (of 54) intervention studies in that category.

\section{Practical implications}

The theoretically grounded and integrated framework developed in the current study has practical implications for teachers' mathematics instruction and professional development. First, the Wheel was developed in response to calls for a more integrative approach to theory and use-inspired research on motivation and engagement (Liem and Martin 2012). The associated quantitative assessment tool - the Motivation and Engagement Scale (Martin 2008) — has helped researchers and practitioners better understand student motivation and engagement. Specifically, the Wheel and scale are effective methods for teacher use when assessing their students' levels of motivation and engagement. We recommend that once teachers assess their students' levels of motivation and engagement - or use the Wheel to guide students' self-assessmentthey move to assessing their own practice with results from the CLASS ${ }^{\mathrm{TM}}$.

Taken together, mathematics teachers can apply our framework as one way to better understand or improve the interactions in their own classrooms. Assessing practice with the CLASS ${ }^{\text {TM }}$ in relation to students' motivation and engagement levels may help a teacher to identify the importance of classroom organisation strategies, particularly since our results found a connection between higher-than-average levels of student motivation and engagement and mathematics teachers' intentional use of classroom organisation strategies. While a significant amount of a teacher's personal and jobrelated resources can be spent on designing a multitude of interactive learning activities, we recommend mathematics teachers ensure they are addressing low or declining motivation and engagement through effective classroom organisation strategies. In addition to the CLASS ${ }^{\mathrm{TM}}$, researchers and professional development providers may also find the Teacher Intentionality of Practice Scale (TIPS; Marshall et al. 2016) useful as it also addresses the importance of teacher-student interactions within a safe, respectful, and well-organised learning environment.

\section{Conclusion}

Much of the effect of teachers and classrooms on student learning relies on interactions (Hamre et al. 2013). Teacher-student relationships have positive and significant associations with academic measures, including motivation, engagement, and performance (Martin et al. 2009). Through our examination of six teachers of mathematics who had students with high levels of motivation and engagement, we harnessed two key theoretical approaches to academic development and instruction in order to analyse broad strategies used by teachers. Future applications of our integrative framework to the study of students' motivation and engagement can enhance our understanding of 
the levels of teacher support deemed most effective in mathematics. In conclusion, the joint operation of a multidimensional theoretical framework and qualitative data can help identify ways teachers can prioritise the interpersonal environment of a mathematics classroom and, in so doing, begin to address the decline in students' mathematical performance during those transitional middle years of schooling.

\section{References}

Anderson, J., Bobis, J., Martin, A. J., Skilling, K., \& Way, J. (2016). The middle years transition, engagement, and achievement in mathematics (MYTEAM) project. Paper presented at the 13th International Congress on Mathematical Education. Hamburg, Germany.

Askew, M., Denvir, H., Rhodes, V., \& Brown, M. (2000). Numeracy practices in primary schools: towards a theoretical framework. Research in Mathematics Education, 2(1), 63-76. doi:10.1080 /14794800008520068.

Askew, M., Rhodes, V., Brown, M., Wiliam, D., \& Johnson, D. (1997). Effective teachers of numeracy: report of a study carried out for the teacher training agency. London: King's College, University of London Retrieved from http://mikeaskew.net/page3/page4/files/EffectiveTeachersofNumeracy.pdf.

Bandura, A. (1997). Self-efficacy: The exercise of control. New York: Freeman.

Bobis, J., Anderson, J., Martin, A. J., \& Way, J. (2011). A model for mathematics instruction to enhance student motivation and engagement. In D. Brahier (Ed.), Motivation and disposition: pathways to learning mathematics, National Council of Teachers of Mathematics seventy-third yearbook (pp. 3142). Reston, VA: NCTM.

Bobis, J., Way, J., Anderson, J., \& Martin, A. J. (2016). Challenging teacher beliefs about student engagement in mathematics. Journal of Mathematics Teacher Education, 19(1), 33-55. doi:10.1007/s10857-0159300-4

Bronfenbrenner, U. (1986). Ecology of the family as a context for human development: Research perspectives. Developmental Psychology, 22(6), 723-742.

Cheon, S. H., \& Reeve, J. (2015). A classroom-based intervention to help teachers decrease students' amotivation. Contemporary Educational Psychology, 40, 99-111. doi:10.1016/j.cedpsych.2014.06.004.

Confrey, J. (2006). Comparing and contrasting the National Research Council Report "On Evaluating Curricular Effectiveness" with the What Works Clearinghouse Approach. Educational Evaluation and Policy Analysis, 28(3), 195-213 http:/www.jstor.org/stable/4121780.

Covington, M. V. (1992). Making the grade: a self-worth perspective on motivation and school reform. New York: Cambridge University Press.

Deci, E. L., \& Ryan, R. M. (2015). Self-determination theory. International Encyclopedia of the Social \& Behavioral Sciences , 21, 486-491. doi:10.1016/B978-0-08-097086-8.26036-4.2nd ed

Durksen, T. L., Chu, M.-W., Ahmad, Z. F., Radil, A. I., \& Daniels, L. M. (2016). Motivation in a MOOC: a probabilistic analysis of online learners' basic psychological needs. Social Psychology of Education: An International Journal, 19(2), 241-260. doi:10.1007/s11218-015-9331-9.

Elliot, A. J., \& McGregor, H. A. (2001). A 2 X 2 achievement goal framework. Journal of Personality and Social Psychology, 80(3), 501-519. doi:10.1037/10022-3514.80.3.501.

Fredricks, J. A., Blumenfeld, P. C., \& Paris, A. H. (2004). School engagement: potential of the concept, state of the evidence. Review of Educational Research, 74, 59-109.

Gettinger, M., \& Walter, M. (2012). Classroom strategies to enhance academic engaged time. In S. L. Christenson, A. L. Reschly, \& C. Wylie (Eds.), Handbook of research on student engagement (pp. 653-673). New York: Springer.

Goetz, T., Bieg, M., Lüdtke, O., Pekrun, R., \& Hall, N. C. (2013). Do girls really experience more anxiety in mathematics? Psychological Science, 24(10), 2079-2087. doi:10.1177/0956797613486989.

Hackenberg, A. J. (2010). Mathematical caring relations. Journal for Research in Mathematics Education, 41(3), 236-273.

Hamre, B. K., Pianta, R. C., Downer, J. T., DeCoster, J., Mashburn, A. J., Jones, S. M., et al. (2013). Teaching through interactions: testing a developmental framework of effectiveness in over 4,000 classrooms. The Elementary School Journal, 113(4), 461-487. doi:10.1086/669616. 
Hanin, V., \& Nieuwenhoven, C. V. (2016). The influence of motivational and emotional factors in mathematical learning in secondary education. Revue européenne de psychologie appliquée, 66, 127-138. doi:10.1016/j.erap.2016.04.006.

Klassen, R. M., Perry, N. E., \& Frenzel, A. C. (2012). Teachers' relatedness with students: an underemphasized aspect of teachers' basic psychological needs. Journal of Educational Psychology, 104(1), 150-165. doi:10.1037/a0026253.

Korpershoek, H., Harms, T., de Boer, H., van Kuijk, M., \& Doolaard, S. (2016). A meta-analysis of the effects of classroom management strategies and classroom management programs on students' academic, behavioural, emotional, and motivational outcomes. Review of Educational Research, 86(3), 643-680. doi:10.3102/0034654315626799.

Liem, G. A. D., \& Martin, A. J. (2012). The motivation and engagement scale: theoretical framework, psychometric properties, and applied yields. Australian Psychologist, 47, 3-13. doi:10.1111/j.17429544.2011.00049.x.

Marshall, J. C., Smart, J., \& Alston, D. M. (2016). Development and validation of Teacher Intentionality of Practice Scale (TIPS): a measure to evaluate and scaffold teacher effectiveness. Teaching and Teacher Education, 59, 159-168. doi:10.1016/j.tate.2016.05.007.

Martin, A. J. (2007). Examining a multidimensional model of student motivation and engagement using a construct validation approach. British Journal of Educational Psychology, 77, 413-440.

Martin, A. J. (2008). The motivation and engagement scale. Sydney: Lifelong Achievement Group www. lifelongachievement.com.

Martin, A. J., Anderson, J., Bobis, J., Way, J., \& Vellar, R. (2012). Switching on and switching off in mathematics: an ecological study of future intent and disengagement amongst middle school students. Journal of Educational Psychology, 104(1), 1-18. doi:10.1037/a0025988.

Martin, A. J., \& Dowson, M. (2009). Interpersonal relationships, motivation, engagement, and achievement: yields for theory, current issues, and educational practice. Review of Educational Research, 79(1), 327365. doi:10.3102/0034654308325583.

Martin, A. J., \& Marsh, H. W. (2006). Academic resilience and its psychological and educational correlates: a construct validity approach. Psychology in the Schools, 43(3), 267-282.

Martin, A. J., Marsh, H. W., McInerney, D. M., \& Green, J. (2009). Young people's interpersonal relationships and academic and nonacademic outcomes: scoping the relative salience of teachers, parents, same-sex peers and opposite-sex peers. Teachers College Record, 23 March. Retrieved from http://www.tcrecord. org/content.asp? contentid $=15593$

Martin, A. J., Way, J., Bobis, J., \& Anderson, J. (2015). Exploring the ups and downs of mathematics engagement in the middle years of school. Journal of Early Adolescence, 35(2), 199-244. doi:10.1177 /0272431614529365.

MCEETYA. (2008). National Assessment Program, Literacy and Numeracy: NAPLAN Summary Report. Carlton South: Ministerial Council on Education, Employment, Training and Youth Affairs. Government of Australia.

Miles, M. B., \& Huberman, A. M. (1994). An expanded sourcebook: qualitative data analysis (2nd ed.). Thousand Oaks, CA: Sage Publications, Inc..

OECD. (2010). Pisa 2009 results: what students know and can do-student performance in reading, mathematics and science, Vol 1. Retrieved from http://www.oecd.org/pisa/pisaproducts/48852548.pdf

Pianta, R. C., \& Hamre, B. K. (2009). Conceptualization, measurement, and improvement of classroom processes: standardized observation can leverage capacity. Educational Researcher, 38(2), 109-119. doi:10.3102/0013189X093323374.

Pianta, R. C., Hamre, B. K., \& Mintz, S. (2012). Classroom assessment scoring system: secondary manual. Charlottesville, VA: Teachstone.

Pietarinen, J., Pyhältö, K., \& Soini, T. (2016). Teacher's professional agency - a relational approach to teacher learning. Learning: Research and Practice, 2(2), 112-129. doi:10.1080/23735082.2016.1181196.

Pintrich, P. R., Smith, D. A. F., Garcia, T., \& McKeachie, W. J. (1991). A manual for the use of the Motivated Strategies for Learning Questionnaire (MSLQ). Ann Arbor, MI: National Center for Research to Improve Postsecondary Teaching and Learning.

QSR International. (2014). NVivo qualitative data analysis, version 10 [computer software]. Cambridge, MA: QSR International Pty Ltd..

Reeve, J., \& Tseng, C.-M. (2011). Agency as a fourth aspect of students' engagement during learning activities. Contemporary Educational Psychology, 36(4), 257-267. doi:10.1016/j.cedpsych.2011.05.002.

Ross, J. A., McDougall, D., Hogaboam-Gray, A., \& LeSage, A. (2003). A survey measuring elementary teachers' implementation of standards-based mathematics teaching. Journal for Research in Mathematics Education, 34(4), 344-363. 
Ryan, R. M., \& Deci, E. L. (2000). Self-determination theory and the facilitation of intrinsic motivation, social development, and well-being. American Psychologist, 55(1), 68-78. doi:10.1037/0003-066X.55.1.68.

Salmela-Aro, K., Kiuru, N., Pietikäinen, M., \& Jokela, J. (2008). Does school matter: the role of school context in adolescents' school-related burnout. European Psychologist, 13(1), 12-23. doi:10.1027/10169040.13.1.12.

Skilling, K. G. (2013). Factors that influence year 7 students' engagement and achievement in mathematics [unpublished doctoral dissertation]. Sydney, Australia: The University of Sydney.

Skilling, K. G., Bobis, J., \& Martin, A. J. (2015). The engagement of students with high and low achievement levels in mathematics. In K. Beswick, T. Muir, \& J. Wells (Eds.) Proceedings of 39th Psychology of Mathematics Education Conference, Volume 4 (pp. 185-192). Hobart, Australia: PME

Skilling, K., Bobis, J., Martin, A. J., Anderson, J., \& Way, J. (2016). What secondary teachers think and do about student engagement in mathematics. Mathematics Education Research Journal, 28(4), 545-566. doi:10.1007/s13394-016-0179-x.

Skilling, K. G., \& Stylianides, G. J. (2015). Promoting cognitive engagement in secondary mathematics classrooms. In Proceedings of the Ninth Conference of the European Society for Research in Mathematics Education (CERME9, 4-8 February 2015, pp. 1280-1286). Prague, Czech Republic: Ninth Conference of the European Society for Research in Mathematics Education (CERME9).

Slavin, R. E., Lake, C., \& Groff, C. (2009). Effective programs in middle and high school mathematics: a bestevidence synthesis. Review of Educational Research, 79(2), 839-911 Retrieved from http://www.jstor. org/stable/40469058.

Way, J., Reece, A., Bobis, J., Anderson, J., \& Martin, A. J. (2015). Improving student motivation and engagement in mathematics through one-to-one interactions. In M. Marshman, V. Geiger, \& A. Bennison (Eds.), Proceedings of 38th Annual Conference of the Mathematics Education Research Group of Australasia (pp. 627-655). Sunshine Coast, Australia: MERGA.

Weiner, B. (1985). An attributional theory of achievement motivation and emotion. Psychological Review, 92(4), 548-573.

Wigfield, A., \& Eccles, J. S. (2000). Expectancy-value theory of motivation. Contemporary Educational Psychology, 25, 68-81.

Yik, M., Russell, J. A., \& Steiger, J. H. (2011). A 12-point circumplex structure of core affect. Emotion, 11(4), 705-731. doi:10.1037/a0023980.

Yin, R. K. (2003). Case study research design and methods (3rd ed.). Thousand Oaks, CA: Sage Publications, Inc.. 